\title{
CORRIGENDUM
}

\section{Radiation interception and conversion to biomass in two potassium-deficient cotton crops in South Benin - CORRIGENDUM}

\section{By E. GERARDEAUX, L. JORDAN-MEILLE AND S. PELLERIN}

doi:10.1017/S0021859608008381, Published by Cambridge University Press, 15 January 2009.

Within this article an incorrect figure was included. The correct figure is shown below.
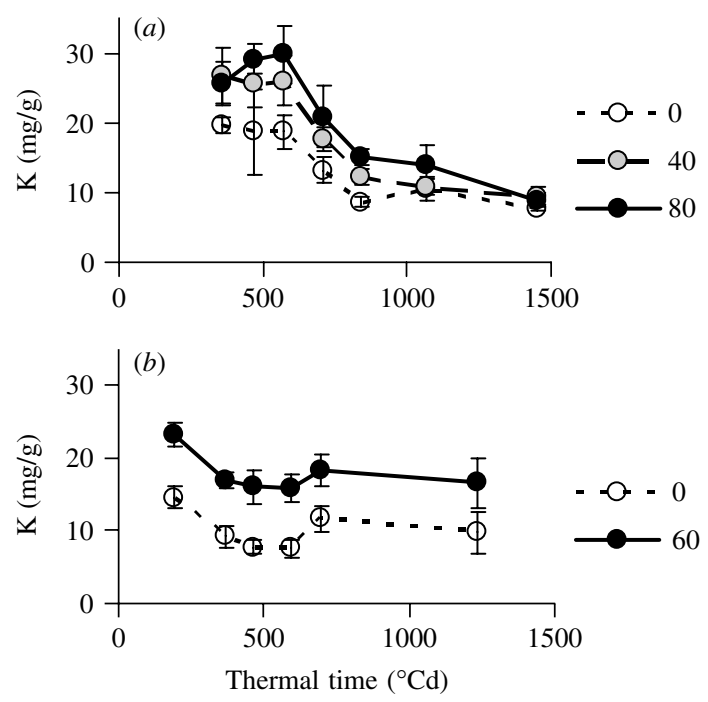

Fig. 7. Leaf potassium concentrations for different K treatments in the Aplahoué-2004 (a) and Savalou-2005 (b) experiments. $\mathrm{K}$ was applied to the soil at $130{ }^{\circ} \mathrm{Cd}$ post-emergence. $\mathrm{K}$ was determined for whole plant leaves and expressed on a dry weight basis. Vertical bars are confidence intervals at $P<0.05$.

\section{REFERENCE}

Gerardeaux, E., Jordan-Meille, L. \& Pellerin, S. (2009). Radiation interception and conversion to biomass in two potassium-deficient cotton crops in South Benin. Journal of Agricultural Science 147, 155-168. 